\title{
The perceived strength of illusory contours
}

\author{
TOM BANTON and DENNIS M. LEVI \\ University of Houston, College of Optometry, Houston, Texas
}

\begin{abstract}
Illusory contours are not well understood, partially because a lack of physical substance complicates their specification via physical standards. One solution is to gauge illusory contours with respect to luminance-defined contours, which are easily quantified physically. Accordingly, we chose a metric (perceived contrast) that expresses illusory contour strength in terms of the physical contrast of luminance-defined contours. Using this metric, adult observers adjusted the contrast of a luminance-defined contour until it matched the perceived contrast of an illusory contour. Illusory contour length, inducer size, and inducer contrast all influenced illusory contour strength. The results are adequately explained via low-level visual processes. It appears that matching paradigms can be beneficial in quantitative studies of illusory contours.
\end{abstract}

The detection and discrimination of luminance contrast are fundamental visual processes that contribute to our ability to perceive edges (Marr, 1982). Many visual functions are known to vary with contrast (Bradley \& Skottun, 1987; Halpern \& Blake, 1988; Panish, 1988; van Nes \& Jacobs, 1981), and so contrast has long been a standard metric for specifying stimulus strength. However, the measurement of illusory contour strength poses a problem: Illusory contours are apparent edges where none exist, and thus have no physically measurable properties such as luminance or contrast. The challenge is to determine which perceptual attributes of illusory contours are appropriate measures of illusory contour strength.

Several attributes might be used to estimate illusory contour strength. Illusory contour figures often appear stratified in depth and appropriately brighter or darker than their background (Petry \& Meyer, 1987). Both apparent depth and perceived figure brightness have frequently been used to specify illusory contour strength (Day \& Kasperczyk, 1983; Halpern, 1981; Halpern, Salzman, Harrison, \& Widaman, 1983; Jory \& Day, 1979; Petry, Harbeck, Conway, \& Levey, 1983; Watanabe \& Oyama, 1988). However, these are attributes of the figures or surfaces formed by illusory contours, and therefore may not reflect the strength of the illusory contours themselves. In fact, illusory contours without apparent depth (Ware \& Kennedy, 1977) and without brightness enhancement (Parks, 1980; Ware, 1981) have been created, suggesting that apparent depth and brightness are not universally useful measures of illusory contour strength. More appropriate measures of illusory contour strength can be found in studies that focus on the differences between contour strength and figure strength. For example, Ware

We thank Susan Petry for her helpful comments on an earlier version of this manuscript. This research was supported by the National Eye Institute through Grants T32EY07024 and F32EY06266 to T. Banton and Grant RO1EY01728 to D. Levi. Address correspondence to T. Banton, Rm. 171 Gilmer Hall, Dept. of Psychology, University of Virginia, Charlottesville, VA 22903 (e-mail: tab2v@virginia.edu).
(1981) used contour salience (the impression of a line or an edge), and Petry et al. (1983) and Siegel and Petry (1991) used contour sharpness (distinctness) to demonstrate that measures of illusory contour strength and brightness reflect different processes. In these instances, salience and sharpness relate specifically to the contours and are therefore reasonable metrics for illusory contour strength.

Although sharpness and salience are particularly useful measures, the perceived contrast of an illusory contour may be a better metric for illusory contour strength. Like sharpness and salience, perceived contrast is specific to the illusory contour, making it applicable to any illusory contour figure. But in addition, perceived contrast quantitatively relates illusory contour strength to the physical contrast of luminance-defined contours, thus making a direct comparison possible. Salience and sharpness probably relate to contrast, but only indirectly. For instance, salience, or the impression of an edge, is a definition that allows factors other than perceived contrast to contribute to illusory contour strength. Sharpness might relate to perceived visibility via changes in perceived line width, as visibility equals contrast times width for widths within the line spread function of the eye (about 1.2' of arc; Campbell \& Gubisch, 1966). However, a more direct relationship between perceived contrast and physical contrast is useful when performance with illusory contours and luminance-defined contours is being compared: thresholds for many tasks vary with contrast, so luminance-defined and illusory contour stimuli should be equated for perceived contrast before making performance comparisons. It is precisely for this reason that we have adopted perceived contrast as a measure of illusory contour strength, since in another study we compare Vernier thresholds for luminance-defined and illusory contour stimuli that are equated for perceived contrast (Banton, 1990).

In designing an illusory contour Vernier stimulus having maximum perceived contrast, we found it necessary to investigate how the perceived contrast of illusory contours changes for several stimulus variables. A magnitude- 
estimation method can provide quantitative measures of perceived contrast if judgments are made relative to a standard having a given contrast, but this method seemed somewhat imprecise to us. For example, Dumais and Bradley (1976) reported illusory contour magnitudes that ranged from $20 \%$ to $96 \%$ of their luminance-defined standard, which was of $92 \%$ contrast. This yields perceived contrasts from $18 \%$ to $88 \%$, which seem paradoxically high for a phenomenon usually reported to be of low contrast. Therefore, magnitude estimates with illusory contours may not directly relate to perceived contrast, so we chose a contrast matching task as a more direct alternative. Observers estimated illusory contour strength by adjusting the contrast of luminance-defined lines to match the perceived strength of illusory contours. These estimates of illusory contour strength were made for different illusory contour lengths, inducer sizes, and inducer contrasts. The results can be explained by assuming that lowlevel visual processes govern illusory contour strength.

\section{EXPERIMENT 1 Line Detection}

Prior to matching luminance-defined lines to illusory contours, a luminance-defined line detection task was conducted so that illusory contour strengths could be specified relative to each observer's luminance-defined line detection threshold. This procedure was meant to reduce the variability that has been reported between observers due to differences in sensitivity to luminance contrast (Klein, Casson, \& Carney, 1990).

\section{Method}

Apparatus and Procedure. Under normal room illumination, observers used their preferred eyes to view a uniformly illuminated (22 cd/ $/ \mathrm{m}^{2}$ ) CRT (Mitsubishi C-3920) from $2.6 \mathrm{~m}$, upon which was displayed a dark $104^{\prime} \times 0.67^{\prime}$ of arc horizontal line. The luminance of the line could be varied from 0 to $77 \mathrm{~cd} / \mathrm{m}^{2}$ in 256 steps by displacing a voltage-sensitive device (trackball) that controlled an IIS image processor. In this way, line strength was varied. As suggested by Klein et al. (1990) for narrow lines, we specified line strength in terms of visibility (contrast $x$ width), because for lines narrower than the eye's line-spread function, the line width affects its visibility. In calculating visibility, line contrast was taken as $\Delta \mathrm{L} / \mathrm{L}_{\text {background. }}$ A method of adjustment was used to estimate line detection threshold. The observers started with a highly visible line, and were instructed to adjust the contrast of the line until it first disappeared. The observers were then shown a uniform field and were asked to increase the line's contrast until it first became visible. Each measure was repeated 5-10 times for each observer, and averages were calculated for the ascending and descending conditions. The mean of each observer's ascending and descending averages was taken as their line detection threshold.

Subjects. Four observers participated in Experiment 1. All the subjects were experienced psychophysical observers from the University of Houston College of Optometry and were normally sighted, as determined by optometric examination. Informed consent was obtained prior to experimental testing. The only observer aware of the purpose of the study was the first author.

\section{Results and Discussion}

Monocular line detection thresholds for the 4 observers in this study ranged from $2 \% \mathrm{~min}$ to $6 \% \mathrm{~min}$ (Figure 1 ),

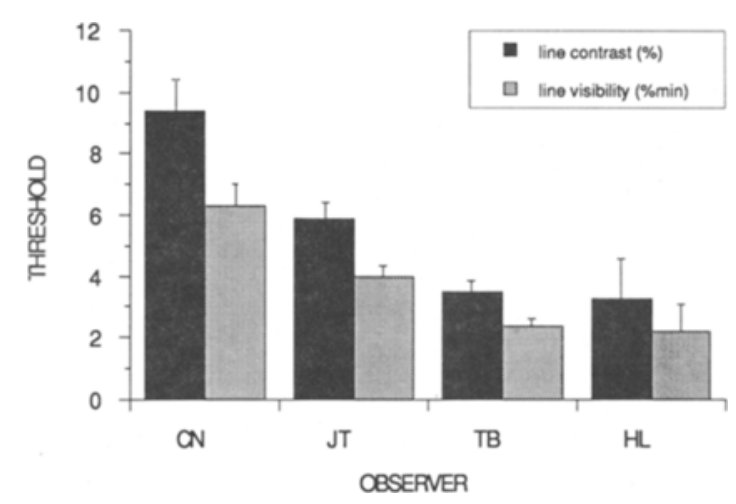

Figure 1. Monocular line detection thresholds used in normalizing illusory contour strength. Thresholds are expressed in terms of line visibility $(\%$ min), which is simply the line contrast $(\%)$ times the line width ( $\mathrm{min})$. This measure was used because line width innuences the visibility of lines narrower than the eye's line-spread function. The thresholds are also presented as percent contrast to orient the reader.

which is consistent with thresholds reported for the detection of a thin line in experiments using forced-choice procedures (Banton \& Levi, 1991; Klein et al., 1990). Therefore, the present paradigm provides a reasonable way to assess line detection thresholds. These data were subsequently used to normalize each observer's estimates of illusory contour strength to their line detection thresholds. Normalization should reduce interobserver variability in illusory contour strength estimates due to sensitivity differences to luminance contrast.

\section{EXPERIMENT 2 Line Matching}

A second experiment was conducted prior to making matches with illusory contours. Luminance-defined lines were matched to luminance-defined lines to ensure that the observers could successfully make matches with this adjustment paradigm.

\section{Method}

Apparatus and Procedure. Three observers from Experiment 1 freely viewed two CRTs that were separated by about $20^{\circ}$ and were equidistant from the observer. Viewing was monocular. The monitor used in the line detection task was on the left, and displayed a $104^{\prime} \times 0.67^{\prime}$ of arc line, the contrast of which the observer could adjust. The right-hand monitor (Sony CPD9000) displayed a thin horizontal line that was designated as the "standard," and that appeared identical in size to the first line. The observers were to adjust the contrast of the line on the left-hand monitor until its visibility was equal to that of the standard line. Viewing duration was unrestricted. The contrast of the standard line was varied in four steps from $18 \%$ to $58 \%$ in a random fashion from trial to trial. Each observer made four to five matches for each line contrast presented; the means of these values are reported here.

\section{Results and Discussion}

The observers accurately estimated the suprathreshold line visibility with the adjustment-based matching paradigm. Figure 2 shows that all the observers made matches 


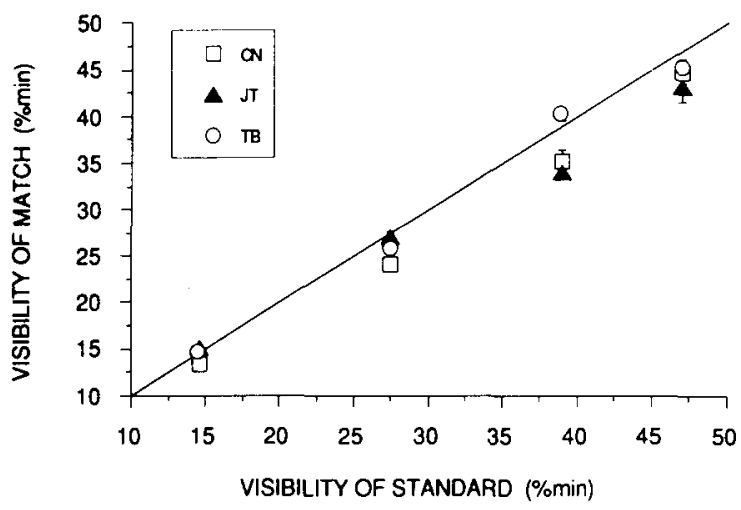

Figure 2. Line matching data from 3 observers. The solid line depicts ideal performance in visibility matching. The results show that visibility matches with suitably low variability can be made with this paradigm.

that were close to the actual line visibilities. As a group, the observers' mean error was $6.2 \% \pm 2.0 \%$ of the standard line visibility, which suggests that the procedure is a reasonable way to estimate visibility. We therefore felt confident in measuring illusory contour visibility with this method.

\section{EXPERIMENT 3 Illusory Contour Matching}

Several variables have been found to influence illusory contour strength. For instance, Petry et al. (1983) and Watanabe and Oyama (1988) showed that illusory contour strength declines as illusory contour length increases. In addition, Petry et al. (1983) reported that inducer size is related to illusory contour strength, although inducer size covaried with illusory contour length. The purpose of Experiment 3 was to verify these two relationships, and to describe them more rigorously in terms of perceived contrast. Thus, the visibility of illusory contours was measured as a function of the inducer separation (equivalent to the illusory contour length) and the inducer size, by using rectangular configurations of "pacman"-shaped "inducers" (Figure 3). The experiment allows us to disambiguate inducer size and illusory contour length.

\section{Method}

Apparatus and Procedure. The 4 observers from Experiment 1 freely viewed the two CRTs used in the line matching experiment. The left-hand monitor again displayed a $104^{\prime} \times 0.67^{\prime}$ of arc horizontal line, whose contrast the observer could adjust. The righthand monitor displayed an illusory rectangle in which the vertical inducer separation was $39^{\prime}$ of arc and the inducing targets were of $86 \%$ contrast. On each trial, the horizontal inducer separation was randomly varied from $18^{\prime}$ to $139^{\prime}$ of arc. In addition, the inducer radius and vertical inducer separation were randomly varied from $4.2^{\prime}$ to $17.6^{\prime}$ of arc and $19^{\prime}$ to $59^{\prime}$ of arc, respectively, for 1 observer. The observers adjusted the contrast of the luminancedefined line until its visibility was equal to that of either of the horizontal illusory contours that formed the illusory rectangle. To maximize the perceived strength of the illusory contours, viewing du- ration was unlimited and fixation was unrestricted, because Bradley (1987) suggests that illusory contours appear stronger when freely viewed than when a fixation target is imposed. A minimum of 4-5 visibility matches were made by each observer under each condition; their normalized means represent the illusory contour strengths reported here.

\section{Results and Discussion}

Figure 4 shows the raw perceived illusory contour strengths (a) and the normalized perceived illusory contour strengths (b) for the 4 observers. The results confirm previous reports by Petry et al. (1983) and Watanabe and Oyama (1988) that illusory contour strength declines as illusory contour length increases. Note that the normalization procedure in Figure $4 \mathrm{~b}$, where the perceived contrast of the illusory contours is specified relative to each observer's line detection threshold, did not change the pattern of results from Figure 4a. Even though the perceived strengths varied between observers by about a factor of 5 after normalization, there was a significant fall in illusory contour strength as inducer separation increased $[F(2,3)=7.387, p<.05]$.

Because the reduction in illusory contour strength with increased inducer separation could reflect a relationship between the illusory contour and its flanking inducers or between the illusory contour and the entire illusory figure, Observer T.B. estimated illusory contour strength for 12 combinations of horizontal and vertical illusory contour lengths as well as for three different inducer sizes. It is interesting that varying the vertical illusory contour length from $19^{\prime}$ to $59^{\prime}$ of arc did not strongly affect T.B.'s estimates of horizontal illusory contour strength (Figure 5). However, the data from Observer T.B. do show an effect of inducer size on illusory contour strength (Figure 6). A direct relationship between inducer size and il-

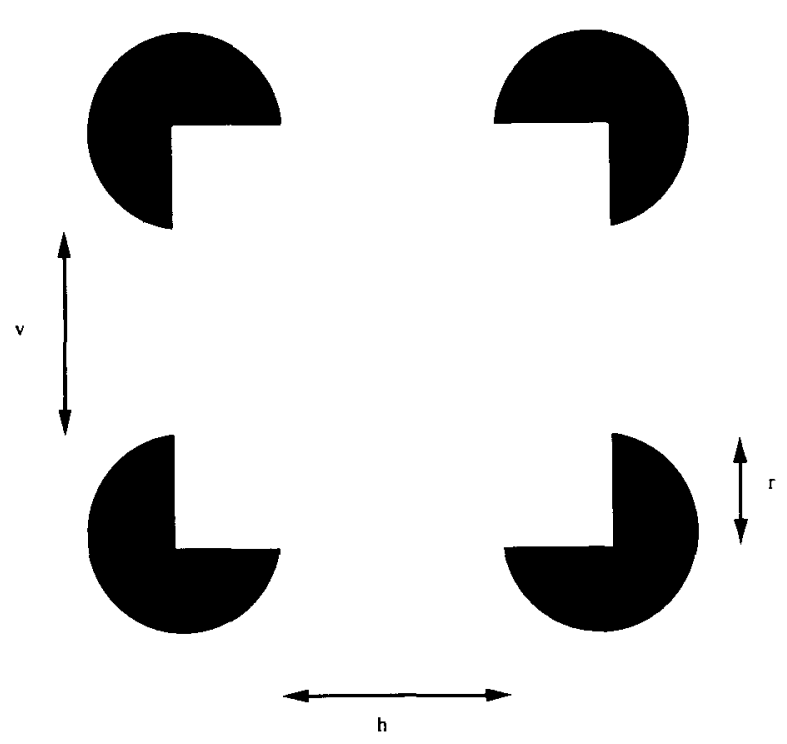

Figure 3. The illusory contour stimulus used in our studies. Horizontal (h) and vertical (v) inducer separation, and inducer radius (r) were varied. Horizontal illusory contour length is equivalent to (h). 

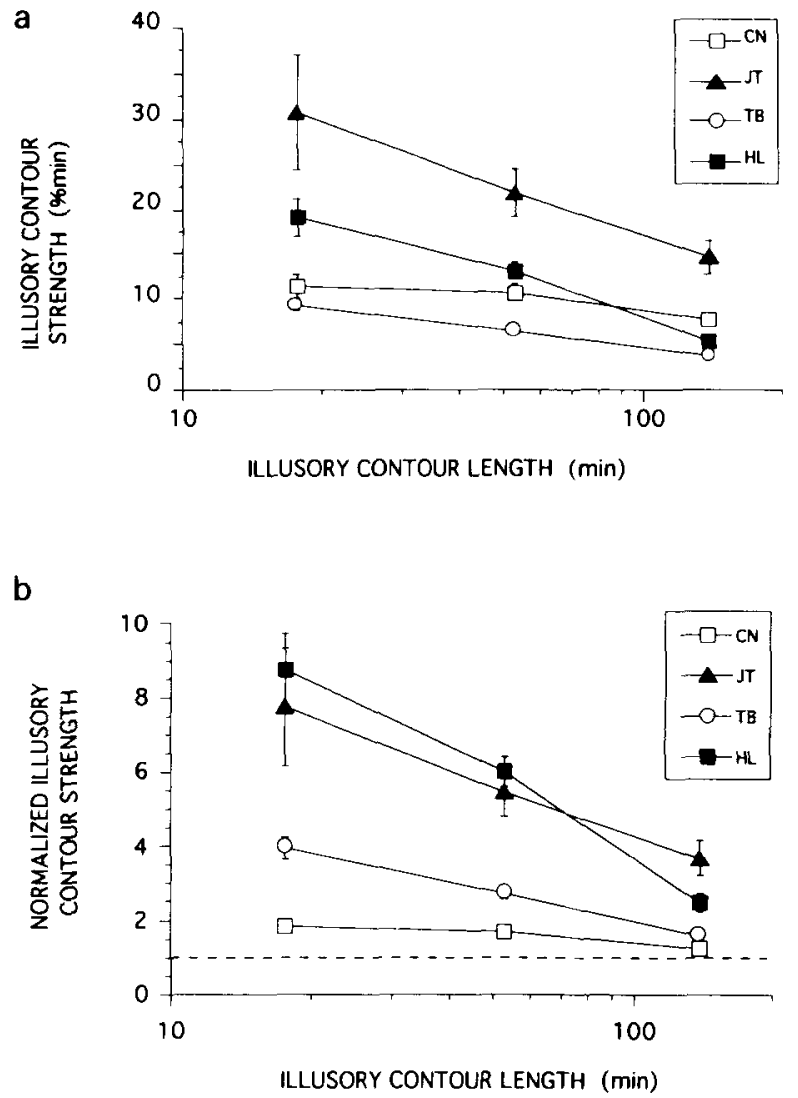

Figure 4. Perceived illusory contour strengths for 4 observers. Inducer radij were 17.6 ' of arc in length. (a) Ilusory contour strength is expressed as the visibility ( $\% \mathrm{~min}$ ) of the matching contour, but can also be expressed as the contrast of the matching contour by dividing the visibilities by the width of the matching line $\left(0.67^{\prime}\right.$ of arc). (b) The data from (a) are normalized to the line detection thresholds of Figure 1. The dotted line, at a value of 1.0 on the abscissa, denotes the illusory contour visibility threshold. In general, illusory contour strength falls as illusory contour length increases.

lusory contour strength has been noted by Petry et al. (1983), who used circular subjective figures, but inducer size covaried with illusory contour length in their experiment. The present experiment allowed us to disambiguate inducer size and illusory contour length by examining illusory contour strength as a function of inducer size when the vertical and horizontal illusory contour lengths were fixed. We found that inducer size affected the perceived strength of illusory contours even when illusory contour length was held constant. Figure 6 shows that when the illusory contours are longer than about $30^{\prime}$ of arc, the two largest inducers are associated with stronger illusory contours. For illusory contours shorter than $30^{\prime}$ of arc, inducer size does not seem to influence illusory contour strength. ${ }^{1}$ Although the reasons for this apparent dichotomy remain to be investigated, perhaps the results with short illusory contours reflect a ceiling on illusory contour strength. The main point, however, is that inducer size can affect the perceived visibility of illusory contours.
The last two findings, that illusory contour strength is influenced by inducer size and is independent of the length of adjacent illusory contours, must be confirmed by other observers. But together the results suggest that illusory contour strength may be governed by variables local to the illusory contour rather than by global percepts derived from the entire illusory figure.

\section{EXPERIMENT 4 Effect of Inducer Contrast}

Previous work suggests that inducer contrast is directly related to illusory contour strength (Ejima \& Takahashi, 1988; Gregory, 1977; Petry et al., 1983). Therefore, we explored this effect by utilizing perceived visibility as our measure of illusory contour strength.

\section{Method}

Apparatus and Procedure. Illusory contour strength was measured at three inducer separations by using high-contrast $(86 \%)$ and low-contrast (18\%) inducers. The low-contrast inducers were created by raising the inducer luminance. Two observers participated in this experiment. All other aspects of the experiment were identical to those of Experiment 3.

\section{Results and Discussion}

Increasing inducer contrast clearly increases perceived illusory contour strength for short illusory contours (Figure 7), which confirms magnitude estimates made by Petry et al. (1983). However, the strength of our longest illusory contours was unaffected by inducer contrast. This result is consistent with the work of Jiang, Flom, and Simpson (1990), who found that illusory contour detection thresholds (illusory contours of maximum length) are unaffected by inducer contrast. The present results and those of Jiang and coworkers suggest that length relations might be adequate for predicting illusory contour strength near illusory contour detection threshold, but length alone is insufficient for determining suprathreshold illusory contour strength.

The role of inducer contrast in determining illusory contour strength may be more complex than our results suggest. Halpern (1981) discusses an experiment by Varin (1971), in which illusory contour figures induced by pacmen made up from concentric circles appeared to be brighter than figures induced by solid pacmen. However, when inducer contrast was calculated by using the average luminance of the inducer, the concentric circle inducers had a much lower contrast than the solid inducers. Although this result is specific to the illusory figure and not illusory contours, it is in direct opposition to the behavior of illusory contours as a function of inducer contrast. It will be interesting to clarify how inducer contrast influences illusory contour strength by quantitatively assessing the perceived contrast of illusory contours formed by concentric circle inducers. However, for the solid inducers we used here, the results are clear: inducer contrast can have a marked effect on illusory contour strength. Furthermore, the sign of the inducer contrast is unlikely 

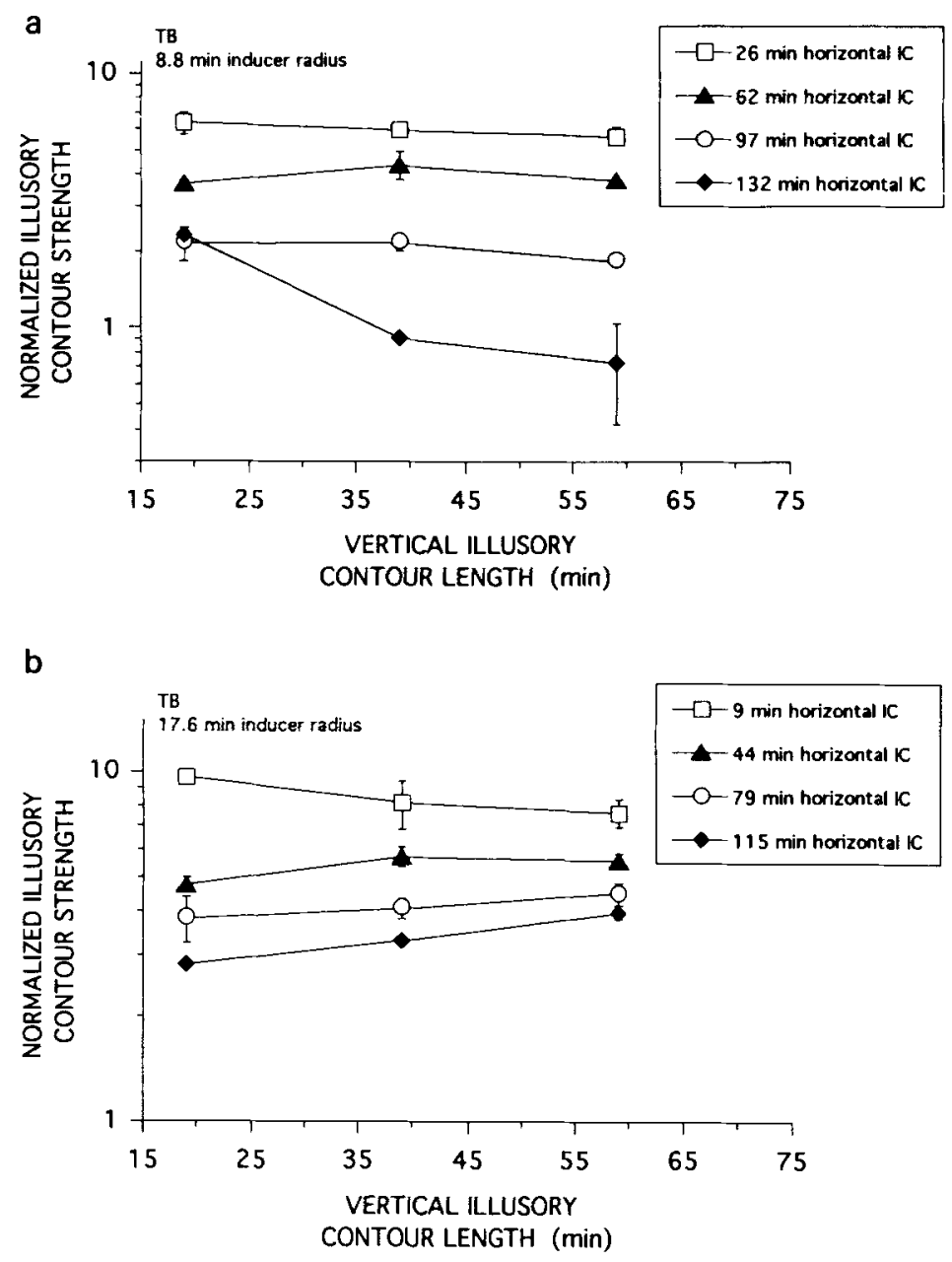

Figure 5. The effect of vertical illusory contour length on horizontal illusory contour strength for Subject T.B. Results from several horizontal illusory contour (horizontal IC) lengths are presented. With inducer radii of $8.8^{\prime}$ of arc (a) and 17.6' of arc (b), vertical illusory contour length has little or no effect on horizontal illusory contour strength. The results show that changes in the illusory contour figure do not always influence illusory contour strength.

to change these results, because previous work suggests that contrast polarity is disregarded in illusory contour perception (Shapley \& Gordon, 1987).

\section{GENERAL DISCUSSION}

The main purpose of this study was to use perceived contrast (or perceived visibility for very thin targets) as a quantitative measure of illusory contour strength, and to show how it can be measured by using a simple matching task. Unlike several other measures of illusory contour strength, perceived contrast is specific to the illusory contour and not the illusory figure. Thus, perceived contrast matches do not capture all aspects of illusory figures, but they do provide quantitative information on illusory contours, which are an important component of illusory figures. In addition, the perceived contrast mea- sure can be applied to illusory contours generated from all types of stimuli, and can relate illusory contour strength directly to luminance-defined target strength. Perhaps the greatest power of this metric is that it provides a means of standardizing measures of illusory contour strength, which allows for comparisons between different illusory contour types.

The data collected with this method showed a fairly high degree of between-subject variability. One reason for this might be that the subjects are indeed perceiving illusory contour strength differently. This would not be surprising, because cognitive factors have been shown to play a role in illusory contour perception (Dumais \& Bradley, 1976; Wallach \& Slaughter, 1988). However, some of these individual differences might stem from the methodology. In these experiments, we chose not to control fixation in an attempt to increase illusory contour strength 


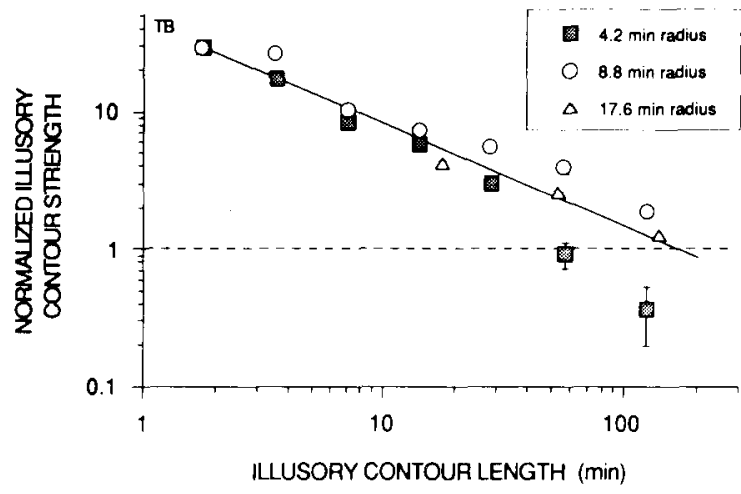

Figure 6. Illusory contour strength as a function of the horizontal illusory contour length when vertical illusory contour length and inducer size are also varied. The dotted line at a value of 1.0 denotes the illusory contour visibility threshold. The solid line depicts the best-fitting power function, $y=(\mathbf{4 4 . 7 3 8})\left(x^{-0.74295}\right)$, and the correlation is .97 . Perceived illusory contour strengths falling below the detection threshold are artifacts of the methodology, and actually reflect illusory contour strengths equal to the detection level (see Note 1). The below-threshold data were adjusted to threshold for the data fitting.

for our observers. However, Petry and Siegel (1989) found that for several sizes of Ehrenstein figures, illusory contour magnitude increased with eccentricity up to $3^{\circ}$, beyond which it fell off again. Between-subject variability could also stem from differences in observers' matching criteria and viewing duration. One should consider controlling these variables in future estimates of illusory contour perceived contrast. But despite the between-subject variability in absolute perceived contrast, the trends found in each of the present experiments were consistent: horizontal illusory contour length, inducer contrast, and inducer size influenced the perceived contrast of horizontal illusory contours, whereas vertical illusory contour length had little or no effect on the perceived contrast of horizontal illusory contours. These findings suggest that illusory contour strength may be derived from visual processes acting locally to the illusory contours. This idea will be developed later in this section.

One criticism of this study might be that illusory contours are like edges rather than lines, and so we should match illusory contours to edges, not lines. We argue that this is not necessary, because the line merely provides a contrast scale against which illusory contour strength may be assessed. This can be done with either a line or an edge. The advantage of using a thin line is that a change in line luminance has little effect on mean luminance, and thus mean luminance did not covary with contrast. In a control experiment, Subject T.B. matched illusory contours to both luminance-defined edges and lines (Figure 8). As expected, line and edge targets gave similar results, as seen by the virtually identical regression line slopes for line and edge targets $(-0.0110$ and -0.0117 , respectively). Illusory contours were of slightly lower perceived strength when edge targets were used in matching, but this difference may reflect the fact that when detection thresholds (primarily edge detection) were estimated, target contrast could not be controlled finely enough to make a precise match. Thus, the difference in illusory contour strengths with these targets may reflect a "rounding error" in the detection thresholds, due to coarse contrast increments at low contrasts. In contrast, a small but true difference with target type may exist. In either case, the main findings of these experiments were not significantly affected by the target selected for matching.

Our data have some bearing on models that attempt to predict illusory contour strength. Several studies have related illusory contour strength to the perimeter of the illusory contour figure (Jiang et al., 1990; Petry et al., 1983), which suggests that it is the proportion of illusory figure length to figure perimeter that determines illusory contour strength. However, we found that varying the vertical illusory contour length (and thus perimeter size) does not affect observers' estimates of horizontal illusory contour strength (see Figure 5). In addition, the data from Figure 6 (illusory contour length versus strength) are replotted as perimeter coverage versus strength in Fig-
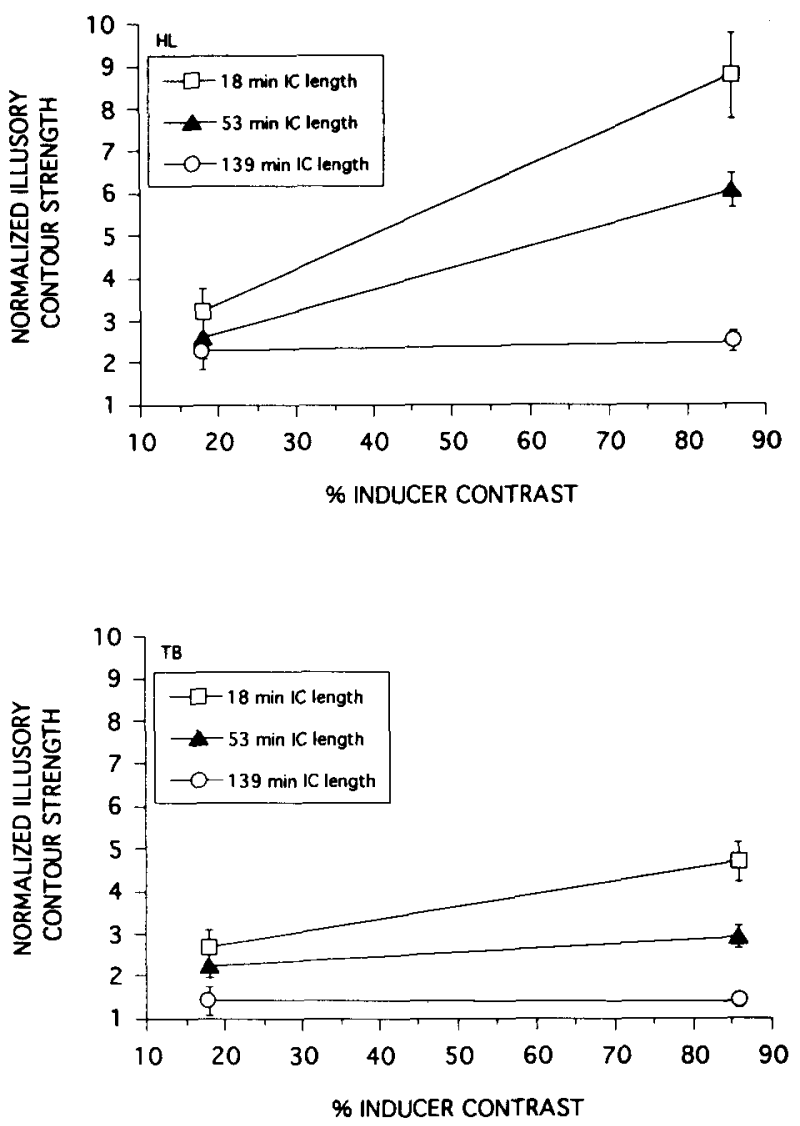

Figure 7. The effect of inducer contrast on perceived illusory contour visibility for 2 observers. Increasing inducer contrast increases illusory contour strength when the illusory contour length is small. At larger illusory contour lengths, inducer contrast plays little role in determining illusory contour strength. 


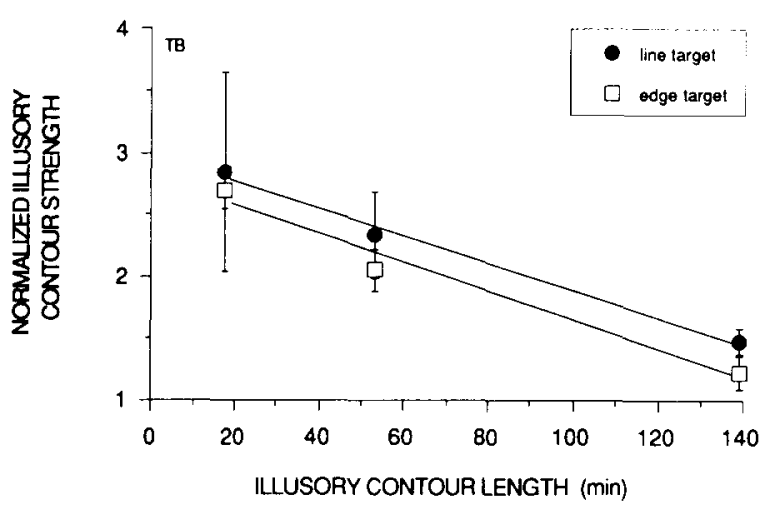

Figure 8. Illusory contour strengths when the matching stimuli are luminance-defined edges and lines. Linear regression lines show that the slopes are unchanged with target type, but illusory contours are perceived to be slightly stronger with line targets.

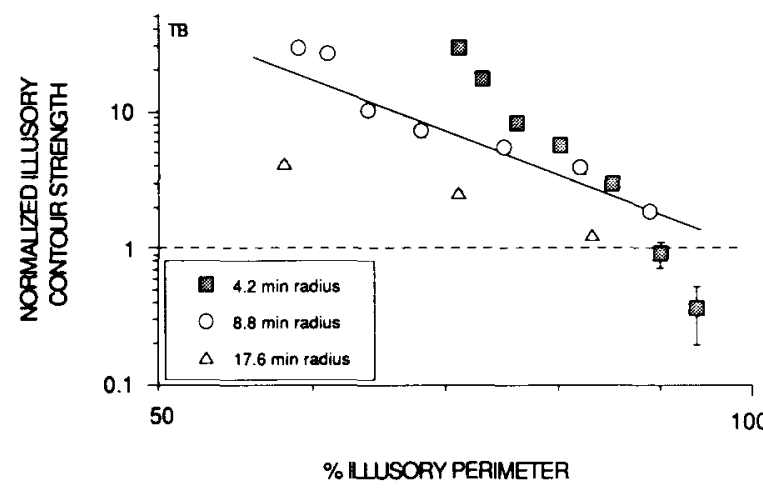

Figure 9. Illusory contour strength as a function of the illusory contour perimeter coverage when vertical illusory contour length and inducer size are also varied. The dotted line at a value of 1.0 denotes the illusory contour visibility threshold. The solid line depicts the best-fitting power function, $y=\left(1.3487 \times 10^{11}\right)\left(x^{-5.5607}\right)$, and the correlation is $\mathbf{. 5 5}$ after adjusting the below-threshold data to threshold. Note that this correlation is much poorer than the correlation between illusory contour strength and illusory contour length in Figure $6(r=.97)$.

ure 9. Illusory contour strength was not as tightly correlated with perimeter coverage $(r=.55)$ as it was with inducer separation $(r=.97)$ when the data were optimally fit with power functions. Thus, there is no advantage to assuming figural determinants of illusory contour strength over factors more local to the illusory contour, such as inducer separation. It appears that illusory contour strength may be largely derived from low-level visual processes acting locally to the illusory contours.

Because illusory contours do not exist without inducing elements, it is of interest to consider how two local variables, illusory contour length and inducer size, might combine to predict illusory contour strength. These two variables are of particular interest because they determine edge length in many illusory figures. For example, in Figure 3 , the length of the base of the illusory square can be described mathematically as $2 r+h$. One measure of illusory contour strength that is derived from these vari- ables is the proportion of illusory contour length to total edge length, or the edge coverage. This is similar to the perimeter idea discussed previously, but it keeps the strength measure local to the illusory contour. If edge coverage is related to illusory contour strength, then the local nature of edge coverage could explain why changes in vertical illusory contour length have little or no effect on illusory contour strength. Figure 10 is a replot of Figure 6, which shows that edge coverage is a good predictor of illusory contour strength ( $r=.85$ with the best-fitting power function to all data in the figure).

In addition, previously reported relationships between figure perimeter and illusory contour strength can be equivalently expressed as edge coverage versus illusory contour strength. For example, Petry et al. (1983) used a circular illusory contour figure to relate the percentage of the circle's perimeter composed of illusory contours to the illusory contour sharpness. But because the inducing elements were equally spaced, illusory contour strength between any two elements is equivalent to illusory contour strength along the entire perimeter of the figure. Similarly, Jiang et al. (1990) related illusory contour detection to percent perimeter covered by illusory contours in an illusory triangle configuration, in which the inducing elements were equidistant from one another at all separations tested. Here also, the percent perimeter covered by the illusory contours was equivalent to edge coverage. Thus, in both experiments, the perimeter measure is equivalent to the more local measure of edge coverage, which suggests that a low-level explanation can predict illusory contour strength without postulating highlevel influences. A low-level explanation for illusory contour strength should not be surprising, because illusory contour detection (Shapley \& Gordon, 1987) and several other illusory contour properties can be explained via lowlevel processes (Dresp \& Bonnet, 1991; Paradiso, Shimojo, \& Nakayama, 1989; Petry \& Siegel, 1989;

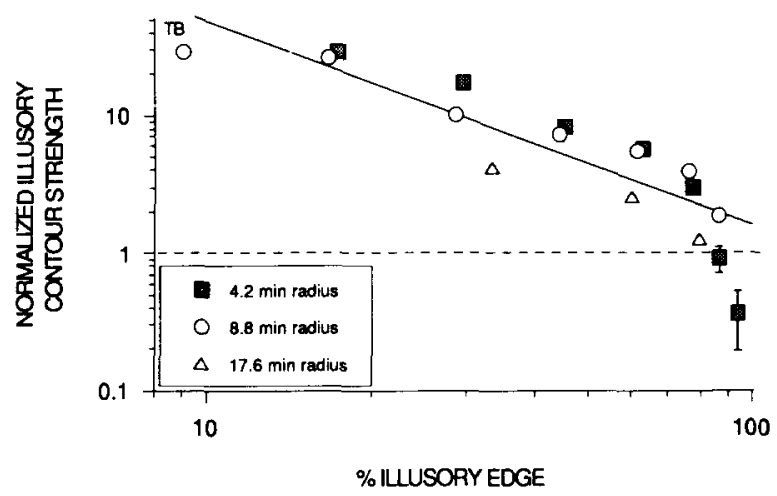

Figure 10. Illusory contour strength as a function of the illusory contour edge coverage when vertical illusory contour length and inducer size are varied. The dotted line at a value of 1.0 denotes the illusory contour visibility threshold. The solid line depicts the bestfitting power function, $y=(1480.5)\left(x^{-1.4845}\right)$, to all data points after adjusting the below-threshold data to threshold. The correlation is .85. Edge coverage appears to be a fairly good predictor of illusory contour strength. 
Pomerantz, Goldberg, Golder, \& Tetewsky, 1981; Purghe, 1989).

Our results are compatible with low-level, hierarchical receptive field models for illusory contours, such as one that was recently elaborated by von der Heydt and Peterhans (1989). Briefly, their model supposes that illusory contours are first defined by $\mathrm{V} 2$ neurons that sum the inputs from line- or edge-sensitive V1 neurons and end-stopped V1 neurons oriented orthogonally to the illusory contour. Such a model can accommodate a nonlinear relationship between illusory contour length and strength; a result that was found at a neuronal level by von der Heydt and Peterhans and at a perceptual level in the present Experiment 3. In addition, the results of Experiment 4 , in which illusory contour strength declined with inducer contrast, are consistent with this low-level model. In this model, one might presume that illusory contour strength is related to the response magnitude of the V2 neurons that define illusory contours. A reduction in inducer contrast should lessen the responses from contrastsensitive V1 neurons, subsequently reducing the input to the V2 neurons that define illusory contours. The result of this scenario is a decline in illusory contour strength as inducer contrast is reduced, which was the result of Experiment 4. Overall, our results are consistent with the idea that low-level processes can account for illusory contour strength.

Although illusory contour strength is well described by low-level processes in the present study, higher level processing might also influence illusory contour strength. For instance, factors such as familiarity (Wallach \& Slaughter, 1988), figural completion (Kanizsa, 1976), and apparent depth (Coren, 1972) have been implicated in regulating illusory contour detection. In addition, several investigators report that low-level luminance contrast is not a prerequisite for illusory contour formation (Ejima \& Takahashi, 1988; Mustillo \& Fox, 1986; Prazdny, 1986). However, it is interesting to note that a four-factor model incorporating both high- and low-level processes (Halpern et al., 1983) accounted for $69 \%$ of the variance in measures of illusory contour strength, whereas our lowlevel illusory contour length hypothesis accounted for $94 \%$ of the variance $\left(r^{2}=.94\right.$ for the power function that best fit the data).

It should be noted that our results were obtained only with illusory contours formed via solid pacman-like inducers. Pacmen created from concentric rings also generate strong illusory contours (Varin, 1971). In this case, the edge coverage hypothesis predicts weak illusory contours because the pacman edges are composed of line ends that cover a very low percentage of the edge. However, one must keep in mind that these line ends form illusory contours along the pacman edges. By taking these virtual pacman edges into account, edge coverage with concentric ring pacmen and solid pacmen would be equal, which would explain the strong illusory contour percept generated with concentric ring inducers. On the other hand, outlined pacmen generate very weak illusory contours at best (Kanizsa, 1974), even though edge coverage with outlined and solid inducers is identical. One possibility is that the mean luminance of outlined pacmen is so close to the background luminance that pacman contrast is insufficient to produce a strong illusory contour. Finally, the edge coverage hypothesis may generalize to illusory contours formed from other types of inducers. For instance, illusory contour strength in Ehrenstein figures should depend on the size, number, and contrast of the inducing lines under an edge coverage hypothesis. Siegel and Petry (1991) report a statistically significant tradeoff between inducer number and illusory contour size in measures of illusory contour distinctness. Thus, edge coverage may be a general principle for determining illusory contour strength, and this would be consistent with the recent notion that illusory contours from different types of inducers are fundamentally similar in nature (Finkel \& Edelman, 1989; von der Heydt \& Peterhans, 1989; Watanabe \& Cavanagh, 1992). Of course, perceived contrasts for several types of inducers must first be measured to evaluate the general applicability of an edge coverage hypothesis.

In conclusion, we suggest that illusory contour strength is primarily determined via low-level processing. However, we recognize that illusory contour strength may be modifiable through higher level processing. Quantifying both high- and low-level processes in a precise manner may allow us to discover how these processes interact to determine illusory contour strength.

\section{REFERENCES}

BANTON, T. (1990). Spatial localization of non-luminance defined contours. Unpublished doctoral dissertation, University of Houston.

BANTON, T., \& LEVI, D. M. (1991). Binocular summation in Vernier acuity. Journal of the Optical Society of America A, 8, 673-680.

Bradley, A., Skottun, B. C. (1987). Effects of contrast and spatial frequency on Vernier acuity. Vision Research, 27, 1817-1824.

Bradley, D. R. (1987). Cognitive contours and perceptual organization. In S. Petry \& G. E. Meyer (Eds.), The perception of illusory contours (pp. 119-119). New York: Springer-Verlag.

Campbell, F. W., Gubisch, R. W. (1966). Optical quality of the human eye. Journal of Physiology, 186, 558-578.

CoRen, S: (1972). Subjective contours and apparent depth. Psychological Review, 79, 359-367.

DAY, R. H., \& KASPERCZYK, R. T. (1983). Amodal completion as a basis for illusory contours. Perception \& Psychophysics, 33, 355-364.

Dresp, B., \& BonNeT, C. (1991). Psychophysical evidence for lowlevel processing of illusory contours and surfaces in the Kanizsa square. Vision Research, 31, 1813-1817.

Dumais, S. T., \& BraDley, D. R. (1976). The effects of illumination level and retinal size on the apparent strength of subjective contours. Perception \& Psychophysics, 19, 339-345.

EJIMA, Y., \& TAKaHASHI, S. (1988). Illusory contours induced by isoluminant chromatic patterns. Vision Research, 28, 1367-1377.

FinkEL, L. H., \& EDELMAN, G. M. (1989). Integration of distributed systems by reentry: A computer simulation of interactive functionally segregated visual areas. Journal of Neuroscience, 9, 3188-3208.

GREGORY, R. L. (1977), Vision with isoluminant color contrast 1. A projection technique and observation. Perception, 6, 113-119.

HALPERN, D. F. (1981). The determinants of illusory-contour perception. Perception, 10, 199-213.

Halpern, D. F., Salzman, B., Harrison, W., \& Widaman, K. (1983). The multiple determination of illusory contours: 2 . An empirical investigation. Perception, 12, 293-303. 
HalPern, D. L., Blake, R. R. (1988). How contrast affects stereoacuity. Perception, 17, 483-495.

Jiang, B., Flom, M. C., \& Simpson, T. (1990). Illusory contours in amblyopia. Optometry \& Vision Science Supplement, 67, 156.

JoRY, M., \& DAY, R. H. (1979). The relationship between brightness contrast and illusory contours. Perception, 8, 3-9.

KanizsA, G. (1974). Contours without gradients or cognitive contours? Italian Journal of Psychology, 1, 93-113.

Kanizsa, G. (1976). Subjective contours. Scientific American, 235, 48-52.

Klein, S. A., Casson, E., \& CARney, T. (1990). Vernier acuity as line and dipole detection. Vision Research, 30, 1703-1719.

MARR, D. (1982). Vision. San Francisco: W. H. Freeman.

Mustillo, P., Fox, R. (1986). The perception of illusory contours in the hypercyclopean domain. Perception \& Psychophysics, 40, 362-363.

PANISH, S. C. (1988). Velocity discrimination at constant multiples of threshold contrast. Vision Research, 28, 193-201.

Paradiso, M. A., Shimojo, S., \& Nakayama, K. (1989). Subjective contours, tilt aftereffects, and visual cortical organization. Vision Research, 29, 1205-1213.

Parks, T. E. (1980). Subjective figures: Some unusual concomitant brightness effects. Perception, 9, 239-241.

Petry, S., Harbeck, A., Conway, J., \& Levey, J. (1983). Stimulus determinants of brightness and distinctness of subjective contours. Perception \& Psychophysics, 34, 169-174.

Petry, S., MeYer, G. E. (1987). The perception of illusory contours. New York: Springer-Verlag.

Petry, S., Siegel, S. (1989). Parametric analysis of subjective contours. Investigative Ophthalmology \& Visual Science Supplement, 30, 254.

Pomerantz, J. R., Goldberg, D. M., Golder, P. S., \& TetewSKY, S. (1981). Subjective contours can facilitate performance in a reaction-time task. Perception \& Psychophysics, 29, 605-611.

Prazdny, K. (1986). Illusory contours from inducers defined solely by spatiotemporal correlation. Perception \& Psychophysics, 39, 175-178.

Purghe, F. (1989). Privileged directions for subjective contours: Horizontal and vertical versus tilted. Perception, 18, 201-213.

Shapley, R., \& GoRDON, J. (1987). The existence of interpolated illusory contours depends on contrast and spatial separation. In S. Petry
\& G. E. Meyer (Eds.), The perception of illusory contours (pp. 109115). New York: Springer-Verlag.

Siegel, S., \& Petry, S. (1991). Evidence for independent processing of subjective contour brightness and sharpness. Perception, 20, 233-241.

vaN NES, F. L., \& JACOBS, J. C. (1981). The effect of contrast on letter and word recognition. IPO Annual Progress Report, 16, 72-80.

VARIN, D. (1971). Fenomeni di contrasto e diffusione cromatica nell organizzazione spaziale del campo percettivo. Rivista di Psicologia, 65, 101-128.

von der Heydt, R., \& Peterhans, E. (1989). Mechanisms of contour perception in monkey visual cortex: 1 . Lines of pattern discontinuity. Journal of Neuroscience, 9, 1731-1748.

Wallach, H., \& SlaUghter, V. (1988). The role of memory in perceiving subjective contours. Perception \& Psychophysics, 43, 101-106.

WARE, C. (1981). Subjective contours independent of subjective brightness. Perception \& Psychophysics, 29, 500-504.

Ware, C., \& KenNedy, J. M. (1977). Illusory line linking solid rods. Perception, 6, 601-602.

Watanabe, T., Cavanagh, P. (1992). Depth capture and transparency of regions bounded by illusory and chromatic contours. Vision Research, 32, 527-532.

Watanabe, T., \& Oyama, T. (1988). Are illusory contours a cause or a consequence of apparent differences in brightness and depth in the Kanizsa square? Perception, 17, 513-521.

\section{NOTE}

1. It must be pointed out that the data that fall below the detection threshold in Figures 5-8 are artifacts of the procedure. The contrast of the matching line was set by computer to $0 \%$ prior to each trial. If the illusory contour standard was not visible to the observer on a given run, the observer could leave the matching contrast at the initial starting point $(0 \%)$, if desired. When this was done, however, it created a situation in which matching contrast could be lower than the detection threshold, and ratios could therefore be lower than 1 . Thus, data falling below the detection threshold actually represent performance at the detection level, and should be treated as such throughout this paper.

(Manuscript received October 22, 1991; revision accepted for publication June 2, 1992.) 